\title{
Factors Affecting the Willingness to Pay for the Protection of the Di River: an Approach Using the Box-Cox Double Hurdle Model
}

\author{
Idrissa Ouiminga (Corresponding author) \\ Department of Economics, Public University of Ouaga 2 \\ 03 BP 7210 Ouagadougou Burkina Faso
}

Tel: 226-7028-2935Ｅ-mail: iouiminga@univ-ouaga2.bf

Lota D. Tamini

Department of Agri-Food Economics and Consumer Sciences, Laval University, Canada

Received: September 22, 2018 Accepted: October 9, 2018 Published: November 6, 2018

doi:10.5296/emsd.v7i4.13681

URL: https://doi.org/10.5296/emsd.v7i4.13681

\begin{abstract}
The Di River, located in West Africa between Burkina Faso and Mali, is a subject of concern to its users. Using econometric models of choice behavior, the determining factors of local populations' willingness to pay (WTP) for the restoration of the riverbanks are either individual or collective variables. The latter variables imply that data collection focused on common characteristics of the population rather than intrinsic characteristics. Most determining factors have a positive effect on willingness to pay, which is especially observed with subjective or individual variables and reflects the very moderate investment that local populations are willing to make. However, that is also indicative of the potential to achieve sustainable management in such a way that personal factors contribute to increasing the WTP. In addition, the variable related to the level of education of a respondent reveals a willingness to pay a nonfinancial contribution for the restoration of the riverbanks and sustainable management of the resource.
\end{abstract}

Keywords: Riverbank, Sustainable management, Willingness to pay, Objective variable, Subjective variable, Natural resources

JEL Classification: Q56, C25, D03 


\section{Introduction}

Climate change affects developing countries because of their limited adaptive capacity (Bauer \& Scholz 2010; Weikmans, 2012). In these countries, and particularly in Africa, the most fertile areas are sometimes overexploited, raising the question of the sustainability of these resources (Bauer \& Scholz 2010). Similar pressure is exerted on water resources as well.

The deterioration of riverbanks by silting, household waste deposition and similar activities, or water pollution by pesticides and insecticides, tend not only to degrade environmental resources of a river but also to reduce the income of those involved in the exploitation of these resources (fishermen, sellers, and processors). This is the case for the Di River. Di is a village in Burkina Faso named after a $150 \mathrm{~km}$ long double flux river going through it. The village has a fishing area, and agriculture and breeding are also performed in the village.

Large hydroagricultural investments cover $^{1}$ the landscape of Di village with the use of fertilizers and pesticides that degrade the environment. The growth of the population and their economic activities increase the quantity of waste, affecting the resources of the region. The pressures on the ecosystem reduce fish production, which has caused the extinction of some fish species in recent decades. For thirty years, the study area has experienced a sharp drop in fish production from 600 tons/ year to 800 tons / year in 1994 (Baijot et al., 1994) to 300 tons / year in 2008 (Coulibaly, 2008).

The study area is the village of Di bordering the river and the island of Toma, a small island in the river. The alternatives offered for restoration are dredging the river, stopping the growth crops along riverbanks, discontinuing indigenous rituals, etc.

The goal of this study is to identify the main variables that affect willingness to pay (WTP) for the protection of these riverbanks along with the variables that influence the amount to be paid for that variable. WTP can be defined as an economic agent's willingness to pay to generate profits, whereas the willingness to receive (WTR) is the compensation value that the agent is ready to receive following the loss or degradation of an environmental asset (Randall, 2002). As an assessment tool, WTP appears to be more appropriate than WTR because for the same environmental good quality variation, the WTR has a higher value than the WTP. This scenario can be explained by the fact that people are more likely to value a good they own, giving it a greater sentimental value than a property they covet (Randall, 2002).

Random utility theory is a utility made up of a deterministic component, which consists of observable attributes characterizing the alternatives, and a stochastic component, which can be measured or observed by researchers. Ndetewio and al. (2013) present the factors influencing the willingness to pay for operating a watershed in Tanzania using a multilinear regression. However, this approach implies the use of zero values for WTP, making the use of ordinary least squares method biased and not acceptable (Maddala, 1985; Long \& al., 2006). In the Heckman correction method (1979), no distinction is made between revealed values of zero and the decision not to participate (Aristei et al., 2008). Although this model allows for

\footnotetext{
${ }^{1}$ The impact of landscape development is addressed by other organizations such as the IUCN and the Sourou Valley.
} 
better estimators and amends the self-selection bias induced by the "zeros", it is not appropriate in this case because no distinction is made between willingness to pay and the amount to be paid (Garcia, 2013). The Tobit model is based on the assumption that the same random process determines the value of the continuous observations of the dependent and dichotomous variables (Blundell \& Meghir, 1987), a very restrictive assumption (Carroll \& al., 2006). In fact, as shown by Liebe et al. (2010), the factors influencing the decision to pay are not necessarily identical to those influencing the WTP.

The P-Tobit model, a restrictive application of the Tobit model, is an alternative to the Tobit model. The P-Tobit model's estimates take into account two steps through the likelihood function written with the probability $\rho$ for the people willing to pay and $1-\rho$ for those who are not (Deaton and Irish, 1984). The P-Tobit seems adequate here but is limited due to the unique value of the parameter $\rho$ for all individuals, although it is impossible to have the same value across all respondents. The double-hurdle model is more appropriate in this case (Cragg, 1971; Martinez-Espinieira, 2006; Saz-Salazar \& al., 2008; Lera-López \& al., 2014).

An element that can result in biased estimators using the double-hurdle model is the nonnormality of the data (Box \& Cox, 1964). To address this deficiency, a Box-Cox variant of the double-hurdle model where the dependent variable is transformed by a change in variable can be considered. This approach incorporates the fact that error terms are not normally and independently distributed (Genanew \& al, 2012; Martinez-Espinieira, 2006; Moffatt, 2005). In addition, there is a presumption of heteroscedasticity because the respondents from the study area have somewhat different profiles.

This model incorporates other models with limited dependent variables and addresses the particular needs of conditioned sequential choices. Martinez-Espinieira (2006) shows through such a model the ability to more accurately assess the behavior of respondents for the preservation of an animal species. Genanew et al. (2012) also use a Box Cox dual-hurdle model to analyze individual decisions by households to start and intensify investment in land conservation.

Education is the main factor motivating people to financially contribute because of the capacities given to people to analyze and understand more about environmental resource protection. The existence of solutions, the nature of suitable solutions and the limited fish supply problem are also positive determinants that lead people to decide to contribute.

Furthermore, the second step reveals that individual factors such as income from fishing or other activities and age positively influence the amount one is willing to pay despite conflicts between farmers and stockbreeders that discourage people from contributing.

The remainder of the paper is structured as follows: Section 2 presents the methodological approach, Section 3 presents the data, Section 4 is devoted to the results of the estimations, and Section 5 concludes the paper.

\section{Methodology}

This section presents the two-step models previously discussed. The base model is the 


\section{Macrothink}

Box-Cox double hurdle that will be compared to the Box-Cox P-Tobit and the Box-Cox Tobit.

\subsection{Box-Cox Double Hurdle}

The dependent variable is:

$$
w t p^{T}=\frac{w t p^{\lambda}-1}{\lambda} \text { With } 0<\lambda<1
$$

The log-likelihood function is:

$$
\log L(\beta ; \sigma ; \alpha)=\sum_{c a p=0} \ln \left[1-\Phi\left(\alpha Z_{i}^{\prime}\right) \Phi\left(\left(\beta X_{i}^{\prime}+\frac{1}{\lambda}\right) / \sigma\right)\right]+\sum_{\text {cap }>0} \ln \left[\Phi\left(\alpha Z_{i}^{\prime}\right) w t p_{i}^{\lambda-1} \sigma^{-1} \phi\left(\left(w t p_{i}^{T}-\beta X_{i}^{\prime}\right) / \sigma\right)\right]
$$

where wtp denotes the willingness to pay; $Z$ is the vector of variables affecting the decision to contribute; and $X$ is the vector of variables influencing the amount to pay.

\subsection{Box-Cox P-Tobit}

The Box Cox P-Tobit is a transformation of the P-Tobit model by introducing the parameter $p$, which is defined as the probability of a respondent to participate or contribute. By changing the dependent variable, the log-likelihood function becomes:

$$
\log L(\beta ; \sigma ; p ; \lambda)=\sum_{0} \ln \left[(1-p) \Phi\left(\left(\beta X_{i}^{\prime}+\frac{1}{\lambda}\right) / \sigma\right)\right]+\sum_{>0} \ln \left[p \cdot w t p_{i}^{\lambda-1} \sigma^{-1} \phi\left(\left(w t p_{i}^{T}-\beta X_{i}^{\prime}\right) / \sigma\right)\right]
$$

Maximizing the likelihood function generates the parameters of the model: $\beta, \sigma, p$ and $\lambda$

\subsection{Box Cox Tobit}

The Box-Cox Tobit model is obtained by the Box-Cox transformation of the dependent variable (Jones and Yen, 2000). The log-likelihood function derived is (reference):

$$
\log L(\beta ; \sigma ; \lambda)=\sum_{0} \ln \left[\Phi\left(\left(\beta X_{i}^{\prime}+\frac{1}{\lambda}\right) / \sigma\right)\right]+\sum_{>0} \ln \left[w t p_{i}^{\lambda-1} \sigma^{-1} \phi\left(\left(w t p_{i}^{T}-\beta X_{i}^{\prime}\right) / \sigma\right)\right]
$$

where $\Phi($.$) and \phi($.$) are the cumulative functions and the density of the normal distribution,$ respectively; $\beta$ is the vector of the coefficient of the explanatory variables in the second hurdle; $\sigma$ is the standard deviation of the error term from the equation of willingness to pay; and $\lambda$ is the likelihood multiplier.

Maximizing the $\log$-likelihood function provides an estimate of the parameters $\beta, \sigma$ and $\lambda$. 


\subsection{Heteroscedasticity and Model Selection}

The models will be compared using the Akaike criterion (1973) and the likelihood ratio (LR) test proposed by Greene (2000).

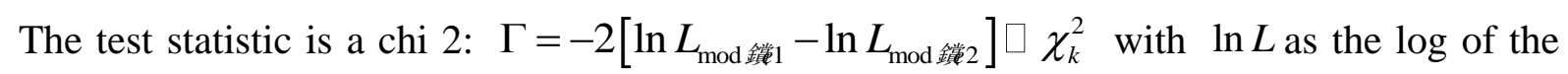
likelihood function and $k$ as the number of independent variables in the equations.

\section{Data}

\subsection{Data Collection}

The questionnaire was divided into a series of questions related to household characteristics, pressure elements, state and vulnerability of the water resources, potential solutions and populations' willingness to pay. Primary data were collected using a sample of 322 people in 2011.

Although time consuming and expensive, a direct interview approach was used in this study because it is suitable for rural areas. Indeed, in comparison to a telephone survey, it helps attain better data and realistic answers.

The method used to collect the data related to the WTP is an open question that helps avoid first-bid and inclusion biases. Table 1 shows the distribution of willingness to pay per gender. Whether the willingness to pay is strictly positive or nonnegative, men are relatively more willing to pay for restoration of the banks.

Table 1. WTP table showing sex of the respondent vs. WTP

\begin{tabular}{|l|l|l|l|}
\hline & \multicolumn{2}{|l|}{ Sex of respondent } & \\
\hline & M & F & Total \\
\hline WTP $\geq 0$ & $53.1 \%$ & $46.90 \%$ & $100 \%$ \\
\hline WTP $>0$ & $55.08 \%$ & $44.92 \%$ & $100 \%$ \\
\hline
\end{tabular}

\subsection{Presentation of Variables}

The variables are presented in Table 2 . The data are primary cross-section data from a survey conducted within the study area.

Table 2. Description of variables

\begin{tabular}{|l|l|l|}
\hline Variables & Description & Nature \\
\hline WTP & $\begin{array}{l}\text { Respondent willingness to pay in } \\
\text { local currency (FCFA) }\end{array}$ & Quantitative \\
\hline First hurdle & \multicolumn{2}{|l|}{} \\
\hline Education & Respondent education level & $1=$ no educational \\
& & $2=$ literate \\
& & $3=$ primary school \\
& & $4=$ secondary school and above \\
\hline
\end{tabular}




\begin{tabular}{|c|c|c|}
\hline Supprob & Fishery product supply problems & $\begin{array}{l}1=\text { no problem } \\
2=\text { existence of problems } \\
3=\text { too many problems }\end{array}$ \\
\hline Solut1 & Existence of possible solutions & $\begin{array}{l}1=\text { no solution } \\
2=\text { existence of solutions }\end{array}$ \\
\hline Solution & Nature of solutions & $\begin{array}{l}1=\text { dredging } \\
2=\text { rituals } \\
3=\text { other alternatives }\end{array}$ \\
\hline \multicolumn{3}{|l|}{ Second hurdle } \\
\hline Fish income & Income from fishing in local currency (FCFA) & Quantitative \\
\hline Waste & Waste dumped in river & $\begin{array}{l}1=\text { yes } \\
2=\text { no }\end{array}$ \\
\hline Other income & Income from activities other than fishing & Quantitative \\
\hline Age & Age of respondent & Quantitative \\
\hline Conflict & Existence of conflicts between users of the banks & $\begin{array}{l}1=\text { no conflicts } \\
2=\text { few conflicts } \\
3=\text { frequent conflicts }\end{array}$ \\
\hline Supprob & Product supply problems & $\begin{array}{l}1=\text { no problem } \\
2=\text { existence of problems } \\
3=\text { too many problems }\end{array}$ \\
\hline Evolconf & $\begin{array}{l}\text { Evolution of conflicts between } \\
\text { farmers and stockbreeders }\end{array}$ & $\begin{array}{l}1=\text { drop } \\
2=\text { steady } \\
3=\text { rise }\end{array}$ \\
\hline
\end{tabular}

The variables explaining the first hurdle are the level of education (education), households' fishery product supply problems (supprob), the existence of a potential solution (solut1) and the nature of the solutions (solution). It is anticipated that a high educational level, the presence of supply problems, and the existence of solutions are the factors that drive the decision to contribute. We expect that the more complex the solutions are, the less people are willing to participate.

In terms of the second hurdle, it is expected that the fishing income, income from other activities, the existence of conflicts between users of the riverbanks, the limited availability of garden produce, and the rise in conflicts between farmers and stockbreeders have positive effects on the willingness to pay. According to economic theory, the greater income is, the higher the probability of contributing. In terms of the conflicts between users of the banks, between farmers and stockbreeders and the supply problems in garden produce, the conflicts depict the extent of the degradation that should, for rational economic agents, lead to making decisions about solving these problems.

In contrast, not dumping household waste in the river is already an effort that could decrease potential contributions, which should in return have an expected negative effect on the amount of contribution from actors.

Table 3 presents the key statistics of the variables used to estimate the willingness to pay. 
Table 3. Description of variables

\begin{tabular}{|l|l|l|l|l|l|}
\hline Variables & Obs. & Mean & Sd & Min & Max \\
\hline WTP* & 322 & 5489.13 & 9128.575 & 0 & 99750 \\
\hline Education $^{*}$ & 322 & 1.667702 & 0.7842772 & 1 & 4 \\
\hline Fish income $^{*}$ & 322 & 551335.4 & 258943.9 & 50000 & 1500000 \\
\hline Supprob & 322 & 1.885093 & 0.3194058 & 1 & 3 \\
\hline Solut1 & 322 & 1.102484 & 0.3037564 & 1 & 2 \\
\hline Solution & 322 & 1.391304 & 0.4951341 & 1 & 3 \\
\hline Age & 322 & 39.18944 & 10.07255 & 25 & 69 \\
\hline Waste & 322 & 1.869565 & 0.3373053 & 1 & 2 \\
\hline Other income & 322 & 307468.9 & 255395.4 & 15000 & 1000000 \\
\hline Conflict & 322 & 1.81677 & 0.3874569 & 1 & 3 \\
\hline Supprob & 322 & 1.649068 & 0.4780044 & 1 & 3 \\
\hline Evolconf & 322 & 1.81677 & 0.3874569 & 1 & 3 \\
\hline
\end{tabular}

(*) Amount in FCFA

\section{Estimation Results and Analysis}

The results of the various estimates are presented in Table 4, while the specification tests are presented in Table 5.

Table 4. Results of estimates based on the methods used

\begin{tabular}{|c|c|c|c|c|c|c|}
\hline \multirow{2}{*}{ First hurdle } & \multicolumn{2}{|l|}{ Box-Cox } & \multicolumn{2}{|c|}{ Box-Coxp-Tobit } & \multicolumn{2}{|c|}{ Box-Cox Double Hurdle } \\
\hline & Coef. & $\begin{array}{l}\text { Robust } \\
\text { std. errors }\end{array}$ & Coef. & $\begin{array}{l}\text { Robust } \\
\text { std. errors }\end{array}$ & Coef. & $\begin{array}{l}\text { Robust std. } \\
\text { errors }\end{array}$ \\
\hline Education & & & & & $0.22 * *$ & $(0.11)$ \\
\hline Supprob & & & & & $0.48 * *$ & $(0.23)$ \\
\hline Solut1 & & & & & $0.34 *$ & $(0.17)$ \\
\hline Solution & & & & & $-1.92 * * *$ & $(0.31)$ \\
\hline Constant & & & & & $1.97 * * *$ & $(0.58)$ \\
\hline$P$ (in p-Tobit) & & & 0.73 & $0.02 * * *$ & & \\
\hline \multicolumn{7}{|l|}{ Second hurdle } \\
\hline Fishincome & $1.66 \mathrm{e}^{-03 * * *}$ & $(0.00)$ & $9.63 \mathrm{e}^{-05 * * *}$ & $(0.00)$ & $9.59 \mathrm{e}^{-06 * * *}$ & $(0.00)$ \\
\hline Waste & -284.25 & (191.72) & -0.21 & $(0.28)$ & -0.21 & $(0.25)$ \\
\hline Other income & $1.82 \mathrm{e}^{-04}$ & $(0.00)$ & $6.88 \mathrm{e}^{-07 * *}$ & $(0.00)$ & $6.85 \mathrm{e}^{-07 * * *}$ & $(0.00)$ \\
\hline Age & 2.78 & $(3.00)$ & $8.3 \mathrm{e}^{-03}$ & $(0.01)$ & $8.26 \mathrm{e}^{-03 * * *}$ & $(0.00)$ \\
\hline Conflict & $124.68 * *$ & $(59.59)$ & $0.37 * * *$ & $(0.13)$ & 0.36 & $(0.17)$ \\
\hline Supprob & $-162.93 * *$ & $(70.48)$ & $-0.66 * *$ & $(0.28)$ & -0.66 & $(0.40)$ \\
\hline Evolconf & 0.32 & $(22.68)$ & $-0.15^{*}$ & $(0.08)$ & $-0.15^{*}$ & $(0.09)$ \\
\hline Constant & 388.26 & $(246.54)$ & $10.98 * * *$ & $(1.02)$ & $10.95 * * *$ & $(2.08)$ \\
\hline$\sigma$ & $516.62 * * *$ & $(111.66)$ & $1.26 * * *$ & $(0.13)$ & $1.25 * * *$ & $(0.47)$ \\
\hline
\end{tabular}




\begin{tabular}{|l|l|l|l|l|l|l|}
\hline$\lambda$ & $0.75^{* * *}$ & $(0.02)$ & $0.15^{* * *}$ & $(0.01)$ & $0.14 * * *$ & $(0.01)$ \\
\hline Sample size $(n)$ & 322 & & 322 & & 322 & \\
\hline$k$ & 10 & & 11 & & 15 & \\
\hline Log likelihood $(\log L)$ & -2349.38 & & -2313.83 & & -2275.73 & \\
\hline AIC $=(-\log L+k) / n$ & 7.32 & & 7.22 & & 7.11 & \\
\hline
\end{tabular}

(a) Robust standard errors in parenthesis.

(b) $* \mathrm{P}<0.10 ; * *<0.05 ; * * *<0.01$.

\subsection{Specification Tests}

To account for heteroscedasticity, estimates are made using the correction of White (1980). Based on the Akaike criterion (AIC), the Box-Cox double hurdle is the best model because it displays the lowest AIC value. For and in-depth analysis, Greene's test results are presented in Table 5.

Table 5. Specification tests comparing the different models

\begin{tabular}{|l|l|l|l|l|}
\hline Models & $\Gamma$ & $\chi_{k}^{2}$ & Comparison of values & Selected model \\
\hline Box-Cox P-Tobit versus Box-Cox Tobit & 71.1 & $\chi_{k}^{2}(1)=3.841$ & $\Gamma>\chi_{k}^{2}$ & Box-Cox P-Tobit \\
\hline Box-Cox DH vs. Box-Cox Tobit & 147.3 & $\chi_{k}^{2}(5)=11,070$ & $\Gamma>\chi_{k}^{2}$ & Box-Cox DH \\
\hline Box-Cox DH vs. Box-Cox P-Tobit & 76.2 & $\chi_{k}^{2}(4)=9,488$ & $\Gamma>\chi_{k}^{2}$ & Box-Cox DH \\
\hline
\end{tabular}

$\mathrm{DH}=$ double hurdle

In terms of preferences, ranked from the highest to the lowest, the Box-Cox double hurdle is first, then the Box-Cox P-Tobit model and finally the Box-Cox Tobit. This result confirms the need to address the issue of identifying the factors affecting willingness to pay in two separate steps, and the factors influencing the decision are different from those determining the WTP (Liebe \& al., 2010).

The reason for selecting the Box-Cox double hurdle as opposed to the double hurdle can also be observed when Henry's graphical approach is applied; see Figure 1 and Figure 2. Figure 1 displays the nonnormality of willingness to pay where the adjustment of scatterplots is curved. Figure 2 is obtained after a Box-Cox change is performed resulting in a linear profile. 


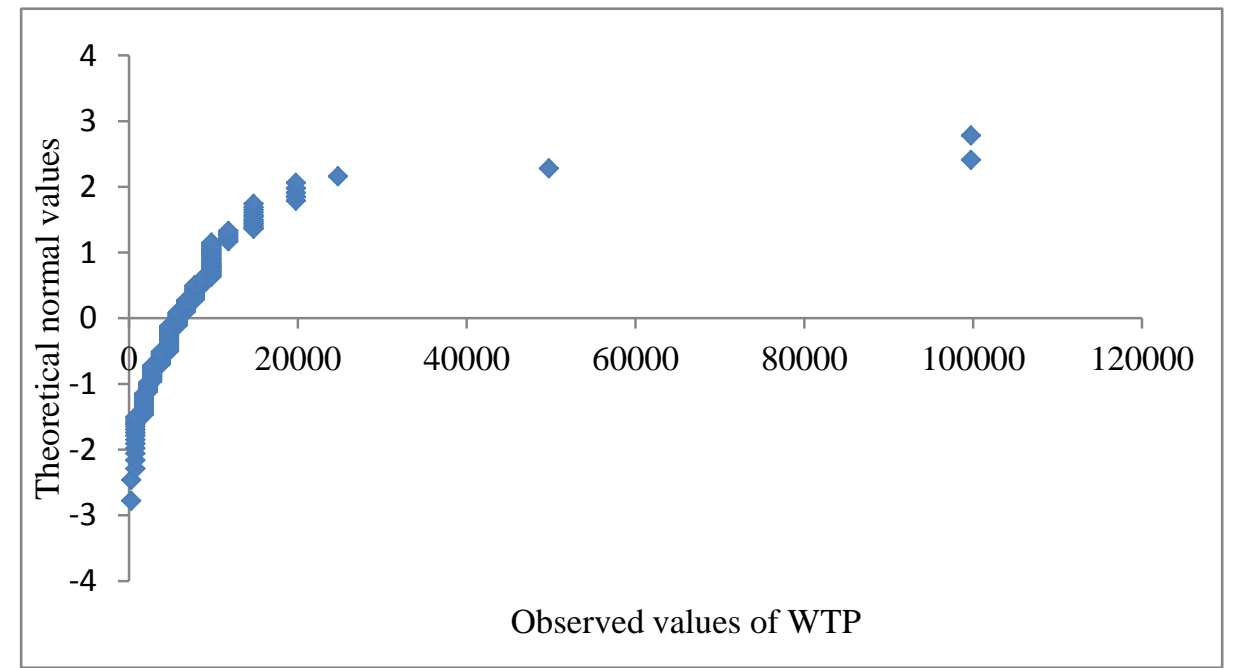

Figure 1. Value of unchanged WTP

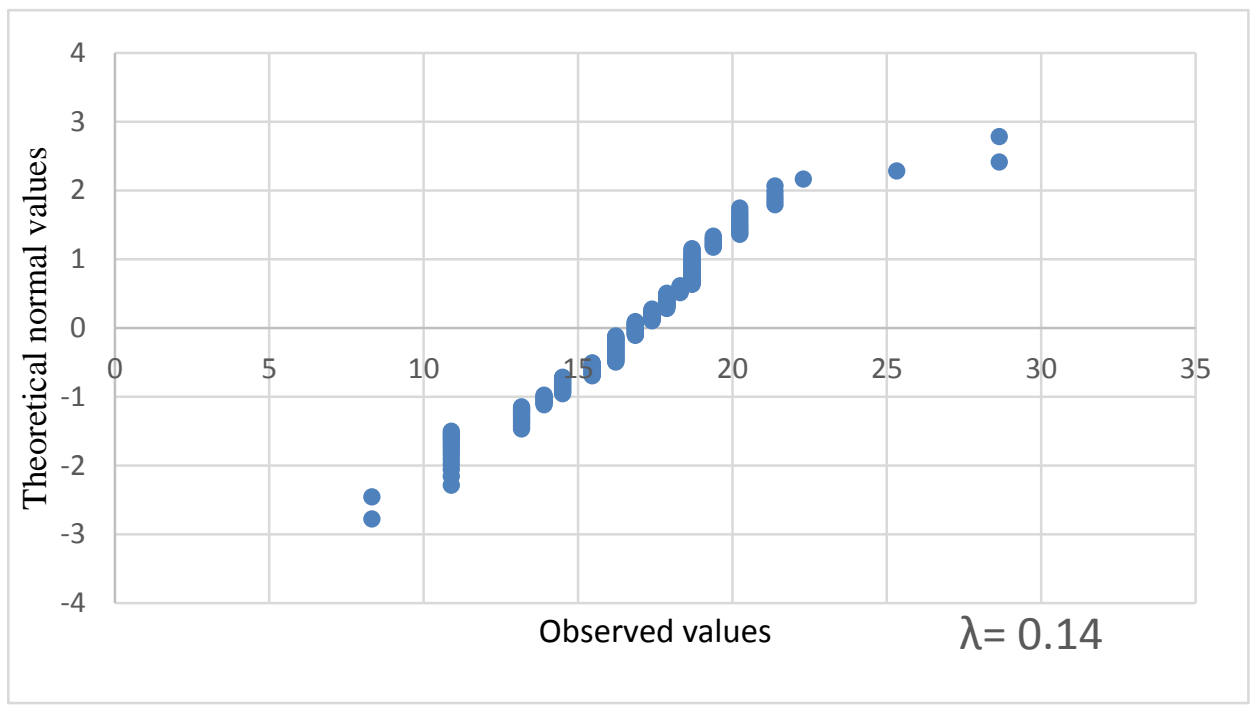

Figure 2. Value of changed WTP

\subsection{Analysis}

\subsubsection{Decision to Contribute}

The analysis of the first step of the double hurdle model, which is the decision to contribute, or not, reveals four significant factors influencing the decision: education, the existence of a solution, the nature of the suitable solution and the limited fish supply problem.

Education has a positive effect on the decision to pay. The higher the education level, the more people will agree to contribute financially to the restoration of the banks. This result is consistent with economic theory to the extent that through education, the respondents understand the challenges (benefits) of restoring an environmental asset.

The second factor is either the absence or existence of a possible solution to riverbank restoration. The positive coefficient for this factor reflects the fact that the more people think 
the problem can be solved, the more they will be willing to contribute. In contrast, some people believe that the riverbank problem is an irrevocable phenomenon that deters them from engaging in any restoration activity.

The third element is the proposed "solution" variable. This variable includes dredging, stopping indigenous rituals in the river and other alternatives. The negative coefficient reflects the fact that the farther the proposed solutions are from dredging, the lower the willingness to contribute is. This is a significant result in the sense that educated economic agents understand that riverbank issues are an environmental and economic problem that needs to be addressed by appropriate, concrete solutions instead of thinking of the issue as something different (a curse or inevitable destiny).

The last factor affecting the decision to contribute to restoration is the problem of seafood supply. A positive coefficient is consistent with the theory that the scarcity of fishery products in the market alerts populations to the existence of riverbank issues, therefore encouraging them to find a solution.

The factors that motivate people to contribute to restoration are relevant and objective given their nature and undeniable effects on populations' decisions related to restoration.

\subsubsection{The Determinant of the WTP}

The Box-Cox double hurdle model analysis of the WTP reveals four significant variables influencing how much people are willing to contribute. These variables are the income generated through fishing, income from activities other than fishing, age and degree of conflicts between farmers and stockbreeders.

Fishing income positively influences WTP; thus, it is expected that the higher the income of people, the higher their financial ability to contribute. The coefficient of income from activities other than fishing also has a positive effect. This result highlights the fact that the availability of resources, regardless of their origin, is a motivating factor for restoring riverbanks. Economic reasons as well as consideration of the environment as a vital resource convince populations to contribute to restoring riverbanks.

Age is the third factor influencing willingness to pay. A positive coefficient shows that older people are the most willing to contribute. Older people consider the environment more important than do younger people. In addition, older people saw the environment when it was in better condition and understand its potential, so they have a greater concern for its restoration.

The variable of the degree of conflict between farmers and stockbreeders is also significant. A negative value reflects the fact that the recurrence of conflicts between these economic actors generally reduces the willingness to pay of local populations. Conflicts create instability and rarely motivate a rational economic agent to invest. In fact, these conflicts can move people off of their land, and ultimately, they can be deprived of their investments.

The analysis also shows that "education", "solutl", "solution" and "supprob" have positive effects and thus contribute positively to motivating people to participate in restoration. 
As indicated previously, the second step allows us to analyze factors influencing the amount of money to be paid. The income generated through fishing and activities other than fishing and respondent age motivate populations to contribute more. In contrast, the repetition of conflicts reduces the amount of money people are willing to commit to restoration.

Age, income from fishing and other activities are specific to a person, whereas conflicts between farmers and herders are experienced by all the actors through the community's social life; therefore, these factors are observed objectively. These are socioeconomic (Halkos \& Matsiori, 2012) and environmental (Shen, 2012) factors reflecting a common will of local actors to address the relevant issue. In short, the factors influencing willingness to pay for restoration of the banks are respondent-based; only conflict between communities is an observable or objective variable, or in other words, it is visible in local people's daily lives.

We can anticipate from these results, a good perspective toward the sustainable management of the Di River because the four factors have largely positive effects. All individual characteristics, "age" "income from fishing", and "income from other activities," of WTP have positive effects on its value.

The desire of the local people to restore the Di riverbanks is real, and their economic behavior is consistent with economic theory. Indeed, for the sustainable management of this resource, the actions of the local actors follow a certain community standard with consent to preserve or establish environmentally friendly practices (Uphoff, 1992).

Moreover, in terms of restoration, sustainable management of the environment in conjunction with significant use of the resources is possible when education and the proposed solutions are considered. Education raises awareness about the exiting problem, and dredging is viewed as an adequate solution. Even if they do not contribute financially, people who become aware of the problem will become involved in its resolution. Their involvement is necessary for the resolution of the problem (Fraser \& al., 2005).

\section{Conclusion}

The factors related to willingness to pay are sometimes linked to individual characteristics and subjective motivations. In terms of the management of natural resources or protected areas, the collaboration of various actors involved is often needed. In general, for sustainable management, it is preferable that the variables or factors affecting the environmental asset be observable rather than subjective. In contrast, as shown by the results of the estimates, these factors are mostly individual characteristics and involve socioeconomic and environmental features. Thus, "age" or "income from fishing or other activities" primarily affect willingness to pay positively.

In a business context, stakeholders are looking for a personal profit, which sometimes leads to a collective benefit. Nonetheless, the pursuit of personal interests in collective action does not lead to good results in all sectors. However, a key factor for sustainable management is the collective contribution of people, which can be in the form of financial contribution. However, even though "social conflicts" can help reduce willingness to pay, the fact remains that sustainable management is possible through collective involvement. In reality, in the case 
of a lack of a financial contribution, increased awareness through education and physical effort that can be measured in financial terms is a way to accomplish sustainable management of an environmental asset. Considering Di River as a public good, the results show that the contribution of the local population might not be enough, but restoration of the banks can still be implemented with the support of public authorities because sustainable management with participation from local populations is possible.

According to Shen (2012), and in this study, only the people who care about the environment are willing to pay. The results of this study confirm this statement, stressing that education is one of the key factors that encourages actors to contribute financially. Through education, awareness of the environment increases the willingness to pay for sustainable management of an asset.

\section{References}

Aristei, D., \& Pieroni, L. (2008). A Double-Hurdle Approach to Modelling Tobacco Consumption in Italy. Applied Economics, 40(19), 2463-2476.

http://doi.org/10.1080/00036840600970229

Baijot, E., Kabore, K., \& Zerbo, H. (1994). Production exploitée et effort de pêche dans les retenues d'eau. Aspects Hydro biologiques et Piscicoles des Retenues d'Eau en Zones Soudano sahélienne. 123-157.

Blundell, R., \& Meghir, C. (1987). Bivariate alternative to the univariate Tobit model. Journal of Econometrics, 34(1-2), 179-200. https://doi.org/10.1016/0304-4076(87)90072-8

Bauer, S., \& Scholz, I. (2010). Adaptation to climate change in southern Africa: new boundaries for sustainable development? Climate and Development, 2(2), 83-93.

http://doi.org/10.3763/cdev.2010.0040

Carroll, J., McCarthy, S., \& Newman, C. (2006). An econometric analysis of charitable donation. The Economic and Social Review, 36(3), 229-249.

Coulibaly, N. D. (2008). Relation longueur-poids chez quatre espèces de poissons de la rivière Sourou au Burkina Faso. International Journal of Biological Chemical Sciences, 2(3), 331-338. http://doi.org/10.4314/ijbcs.v2i3.39744

Cragg, J. G. (1971). Some statistical models for limited dependent variables with application to the demand for durable goods. Econometrica, 39(5), 829-844.

http://doi.org/10.2307/1909582

Fraser, E., Dougill, A., Mabee, W., Reed, M., \& McAlpine, P. (2005). Bottom up and top down: Analysis of participatory processes for sustainability indicator identification as a pathway to community empowerment and sustainable environmental management, Journal of Environmental Management, 78(2), 114-127. http://doi.org/10.1016/j.jenvman.2005.04.009

Garcia, B. (2013). Implementation of a double-hurdle model. The Stata Journal, 13(4), 776-794. 


\section{Macrothink}

Environmental Management and Sustainable Development

ISSN 2164-7682

2018, Vol. 7, No. 4

Genanew, B. W., \& Alemu, M. (2012). Investments in Land Conservation in the Ethiopian Highlands: A Household Plot-level Analysis of the Roles of Poverty, Tenure Security, and Market Incentives. International Journal of Economics and Finance, 4(6), 32-50.

https://doi.org/10.5539/ijef.v4n6p32.

Greene, W. (2000). Econometric Analysis. (4th ed.). Upper Saddle River, New Jersey: Prentice Hall

Halkos, G., \& Matsiori, S. (2012). Determinants of willingness to pay for coastal zone quality improvement. The Journal of Socio-Economics, 41(4), 391-399.

https://doi.org/10.1016/j.socec.2012.04.010

Heckman, J. (1979). Sample selection bias as specification error. Econometrica, 47(1), 153-162. https://doi.org/10.2307/1912352

Jones, A. M., \& Yen, S. T. (2000). A Box-Cox Double-Hurdle model. The Manchester School, 68(2), 203-221. https://doi.org/10.1111/1467-9957.00190.

Lera-Lopez, F., Faulin, J., Sanchez, M., \& Serrano, A. (2014). Evaluating factors of the willingness to pay to mitigate the environmental effects of freight transportation crossing the Pyrenees. Transportation Research Procedia, 3, 423-432.

https://doi.org/10.1016/j.trpro.2014.10.023

Long, J., \& Freese, J. (2006). Regression Models for Categorical Dependent Variables Using Stata, (2nd ed.). College Station, Texas: Stata Press Publisher.

Liebe, U., Preisendörfer, P., \& Meyerhoff, J. (2010). To Pay or Not to Pay: Competing Theories to Explain Individuals' Willingness to Pay for Public Environmental Goods, Environment and Behavior, 43(1), 106-130. https://doi.org/10.1177/0013916509346229

Maddala, G. S. (1985). Limited-dependent and qualitative variables in Econometrics, American Journal of Agricultural Economics, 67(2), 455-456.

https://doi.org/10.2307/1240728

Martinez-Espinieira, R. (2006). A Box-Cox Double-Hurdle model of wildlife valuation: The citizen's perspective. Ecological Economics, 58(1), 192-208.

https://doi.org/10.1016/j.ecolecon.2005.07.006

Moffatt, P. G. (2005). Hurdle models of loan default. Journal of the Operational Research Society, 56(9), 1063-1071. https://doi.org/10.1057/palgrave.jors.2601922

Ndetewio, P. I., Mwakaje, A. G., Mujwahuzi, M., \& Ngana, J. (2013). Factors influencing willingness to pay for watershed services in lower Moshi, Pangani Basin, Tanzania. International Journal of Agriculture \& Environment, 02, 57-75.

Randall, A. (2002). Valuing the outputs of multifunctional agriculture. European Review of Agricultural Economics, 29(3), 289-307. https://doi.org/10.1093/eurrag/29.3.289

Saz-Salazar, S. D., \& Rausell-Köster, P. (2008). A Double-Hurdle model of urban green areas valuation: dealing with zero responses. Journal Landscape and Urban Planning, 84(3-4). 


\section{Macrothink \\ Environmental Management and Sustainable Development \\ ISSN 2164-7682 \\ 2018, Vol. 7, No. 4}

241-251. https://doi.org/10.1016/j.landurbplan.2007.08.008

Shen, J. (2012). Understanding the Determinants of Consumers' Willingness to Pay for Eco-Labeled Products: An Empirical Analysis of the China Environmental Label. Journal of Service Science and Management, 5, 87-94. https://doi.org/10.4236/jssm.2012.51011

Uphoff, N. (1992). Local institutions and participation for sustainable development. Gatekeeper Series, 31.

Weikmans, R. (2012). Le coût de l'adaptation aux changements climatiques dans les pays en développement, VertigO., 12 (01). 1-21. http://doi.org/10.4000/vertigo.11931.

\section{Appendix - Double hurdle model specification}

Let $d_{i}$ be the decision variable for each respondent with $d_{i}=1$ if the respondent decides to contribute and 0 if otherwise. That variable is linked the variable $d_{i}^{*}$ that is a latent variable describing the decision to contribute or not, so that:

$$
\text { A1. } d_{i}^{*}=\alpha Z_{i}+u_{i}
$$

where $Z$ is the vector of variables explaining the decision to contribute, $\alpha$ is the vector of parameters associated with $Z$ and $u_{i}$ is the error term so that $u_{i} \square N(0 ; 1)$

Furthermore, let $w t p_{i}$ and $w t p_{i}^{*}$ respectively be the observed and latent values, respectively, of the willingness to pay of each respondent so that:

$$
\text { A2. } w t p_{i}^{*}=\beta^{\prime} X_{i}+v_{i}
$$

where $X$ is the vector of variables explaining the amount the respondent is willing to pay, $\beta$ is the vector of parameters linked with $X$ and $v_{i}$ is the error term as $v_{i} \square N\left(0 ; \sigma^{2}\right)$. The system is as follows:

Contribution equation

$$
\text { A3. }\left\{\begin{array}{lll}
d_{i}=1 & \text { si } & d_{i}^{*}>0 \\
d_{i}=0 & \text { si } & d_{i}^{*} \leq 0
\end{array}\right.
$$

WTP equation 


$$
\text { A4. }\left\{\begin{array}{lll}
w t p_{i}=w t p_{i}^{*} & \text { si } & w t p_{i}^{*}>0 \mid d_{i}=1 \\
w t p_{i}=0 & \text { si } & w t p_{i}^{*} \leq 0 \mid d_{i}=1
\end{array}\right.
$$

If the decision to participate and the amount of the contribution are independent, then we have two separate models: probit and OLS (Martinez-Espinera, 2006). However, as previously stated, the two decisions cannot be considered isolated at first. Dependence in decision-making occurs in the context of a connection between the two terms of the error. By defining $\rho$ as the correlation coefficient between the two error terms and the covariance matrix, we have:

$$
\Lambda=\left(\begin{array}{cc}
1 & \varphi^{\sigma_{u_{i} ; v_{i}}} \\
\varphi^{\sigma_{u_{i} ; v_{i}}} & \sigma^{2}
\end{array}\right) \text { with } \sigma_{u_{i} ; v_{i}}=\sigma_{u_{i}} \cdot \sigma_{v_{i}},\left(\begin{array}{l}
u_{i} \\
v_{i}
\end{array}\right) \square N(0 ; \Lambda)
$$

The log-likelihood function becomes:

$$
\text { A5. } \log L(\beta ; \sigma ; \alpha)=\sum_{0} \ln \left[1-\Phi\left(\alpha Z_{i}^{\prime}\right) \Phi\left(\beta X_{i}^{\prime} / \sigma\right)\right]+\sum_{>0} \ln \left[\Phi\left(\alpha Z_{i}^{\prime}\right) \sigma^{-1} \phi\left(\left(w t p_{i}-\beta X_{i}^{\prime}\right) / \sigma\right)\right]
$$

If maximized, then it is possible to estimate the required parameters. However, to avoid inconsistent estimators related to the strong assumption of normality and independence of the error terms and the possible presence of heteroscedasticity in this case with the double hurdle model, an option is to use the Box-Cox double hurdle model.

\section{Copyright Disclaimer}

Copyright for this article is retained by the author(s), with first publication rights granted to the journal.

This is an open-access article distributed under the terms and conditions of the Creative Commons Attribution license (http://creativecommons.org/licenses/by/3.0/). 